\title{
Inhibition of return is composed of attentional and oculomotor processes
}

\author{
ALAN KINGSTONE \\ University of British Columbia, Vancouver, British Columbia, Canada \\ and \\ JAY PRATT \\ University of Toronto, Toronto, Ontario, Canada
}

\begin{abstract}
Response time can be delayed if a target stimulus appears at a location or object that was previously cued. This inhibition of return (IOR) phenomenon has been attributed to a delay in activating attentional or motor processes to a previously cued stimulus. Two experiments required subjects to localize or identify a target stimulus. In Experiment 1, the subjects' eyes were not monitored. In Experiment 2, the subjects' eyes were monitored, and the subjects were instructed to either execute or withhold an eye movement to a target stimulus. The results indicated that IOR was always present for location and identification responses, supporting an attentional account of IOR. However, IOR was larger when eye movements were executed, indicating that a motor component can contribute to IOR. Finally, when eye movements were withheld, IOR was larger when a target was presented alone than when it was presented with a distractor, suggesting that IOR is larger for exogenous than for endogenous covert orienting. Together, the data indicate that IOR is composed of both an oculomotor component and an attentional component.
\end{abstract}

Visual attention can be directed endogenously (i.e., volitionally) or exogenously (i.e., reflexively) to specific locations (or objects) in the visual field. When either shift is accomplished by moving the head and/or the eyes, the shift in attention is overt. When a shift in attention is accomplished without any concomitant overt changes, the shift is covert. Both types of shifts (exogenous and endogenous) and both types of orienting (overt and covert) typically benefit the acquisition of stimulus information at the attended location or object, with a cost of reduced processing efficiency for stimulus information at unattended locations or objects. Behaviorally, the result is that response time (RT) and/or response errors are smaller for attended locations/stimuli, relative to unattended locations/stimuli.

There are, however, some interesting behavioral differences between exogenous and endogenous orienting (see Klein, Kingstone, \& Pontefract, 1993; Rafal \& Henik, 1994; Yantis, 1996). As compared with endogenous orienting, exogenous orienting is more rapid (Cheal \& Lyon, 1991; Müller \& Findlay, 1988), is difficult to inhibit (Müller \& Rabbitt, 1989), is unaffected by a concurrent

\footnotetext{
This research was supported by grants to A.K. from the Alberta Heritage Foundation for Medical Research (0134) and the Natural Sciences and Engineering Research Council of Canada (173218 and 170077) and by grants to J.P. from NSERC (194537). We thank MaryLou Cheal, Brad Gibson, and Tram Neill for their insights and feedback on a previous version of this paper. Correspondence concerning this article should be addressed to A. Kingstone, Department of Psychology, University of British Columbia, Vancouver, BC V6T 1Z4, Canada (e-mail: alan@cortex.psych.ubc.ca).
}

task (Jonides, 1981), and is critical for the proper conjunction of stimulus features (Briand \& Klein, 1987; but see Tsal, 1989). It also appears that both forms of orienting can be activated simultaneously but are subserved by different neural mechanisms (Corbetta, Miezin, Shulman, \& Petersen, 1993; Kingstone, Grabowecky, Mangun, Valsangkar, \& Gazzaniga, 1997; Posner \& Peterson, 1990; Rafal \& Henik, 1994).

One other key difference is that covert exogenous orienting produces a biphasic RT performance pattern. When attention is drawn to a peripheral location by the abrupt onset of a luminance cue, RTs to detect targets that appear at the cued location are initially shorter than RTs to detect targets that appear at noncued (i.e., unattended) locations. However, when the cue-target interval exceeds several hundred milliseconds, RTs to detect targets that appear at the cued location become longer than RTs to detect targets that appear at noncued locations. Posner and Cohen (1984) attributed this lengthening of RT to a mechanism that inhibits attention from returning to a cued location and suitably called the effect inhibition of return (IOR).

An alternative explanation for IOR was recently advanced by Klein and Taylor (1994). They suggested that a peripheral cue may activate a spatially directed motor response to the cued location. To avoid responding to the cue, the motor response is inhibited. If a target then appears at the cued location, which calls for the execution of the inhibited response, IOR is observed. Pratt, Kingstone, and Khoe (1997) tested the attention and motor hypotheses directly by requiring subjects to execute a manual response that either localized or identified the target 
stimulus. The motor explanation predicted that IOR would occur for a localization response but not for an identification response, because the localization response was spatially directed, whereas the identification response was not. The attentional explanation predicted that IOR would occur for both responses, because attention would be inhibited from returning to the cued location, regardless of the nature of the response.

In three experiments (Pratt et al., 1997), subjects indicated, with a two-choice keypress response, whether a target stimulus appeared to the left or the right of a central fixation point (localization task) or whether a target stimulus was an $\mathrm{X}$ or a + (identification task). In the localization task, a target and a nontarget appeared simultaneously on either side of central fixation. In the identity task, a target stimulus appeared on its own (Experiments 1 and 2) or simultaneously with a nontarget (Experiment 3 ).

The results indicated that an IOR effect was always observed in the location and identity tasks, providing clearcut support for an attentional account of IOR. In addition, and crucial to the present study, a larger IOR effect was observed in the identity task than in the location task when a target was presented in isolation (Experiments 1 and 2). When an identity target was presented with a nontarget (Experiment 3), the magnitude of the IOR effect was the same as that in the location condition.

This variation in the magnitude of the IOR effect as a function of whether target onset was accompanied by a nontarget suggested to Pratt et al. (1997) that the IOR effect may depend on the type of covert attention that is directed to a target stimulus. On the basis of previous research, it was hypothesized that when a target appeared in isolation, orienting to the target was under exogenous control and that when the target was accompanied by a nontarget, orienting to the target was primarily under endogenous control (see, e.g., Yantis \& Jonides, 1990). Thus, the finding that the IOR effect was larger when a target appeared alone suggested that IOR was larger for exogenous orienting than for endogenous orienting.

However, there is an alternative explanation for why IOR was reduced in the identity task in Experiment 3. In that experiment, eye monitoring was introduced, effectively eliminating the contribution of eye movements to RT performance. This is important, because it is reasonable to think that, in the previous experiments, in which eye movements were not monitored, subjects were more likely to execute eye movements to the target in the identity task than in the localization task, because the identity task required detailed visual discrimination of the target stimulus. Thus, it is possible that the IOR magnitude in the identity condition was reduced in Experiment 3 because eye movements were controlled for, rather than because a nontarget co-occurred with the target stimulus. The implication of this hypothesis is that a localization response to the target stimulus, such as an eye movement, might contribute to the magnitude of the IOR effect. Such a finding would be strongly consistent with the motor explanation of IOR.

To summarize, in support of an attention explanation of IOR, Pratt et al. (1997) found that IOR occurred for both target localization and target identification responses. In the first two experiments, a nontarget was presented with a target in the localization task, but not in the identification task. In these experiments, IOR was larger in the identification task. In a third experiment, a nontarget was added to the identification task, and eye monitoring was introduced. In this experiment, the IOR effect was reduced in the identity task to the magnitude observed in the localization task. Two accounts are possible for the finding that IOR was reduced in Experiment 3 . The attentional account, suggested by Pratt et al., is that IOR is smaller when attention is committed endogenously, rather than exogenously, to a target stimulus. The motor account is that IOR is reduced when an oculomotor target localization response is eliminated. The goal of the present paper was to test between these alternative interpretations.

\section{EXPERIMENT 1}

The first experiment was a natural extension of the experiments reported by Pratt et al. (1997). Recall that, in Pratt et al., subjects performed a target localization task or a target identification task. In the localization task, a nontarget was always presented with a target. In the identification task, either a target appeared in isolation (and eye monitoring was omitted) or a target appeared with a nontarget (and eye monitoring was included).

The goal of the present experiment was to examine the pattern of IOR for target localization and target identification tasks when eye movements were not monitored and targets were presented in isolation or with nontargets.

\section{Method}

Subjects. Twenty-four undergraduate observers from the University of Alberta participated in a single 1 -h session. All the subjects had normal or corrected-to-normal vision and received course credit for their participation.

Apparatus and Procedure. The subjects were seated $57 \mathrm{~cm}$ in front of a MicroScan 5EP/AO1 computer monitor. A computer keyboard was placed directly in front of the subjects.

White stimuli were presented on a black background. The stimuli were drawn from a set of seven items: a fixation dot positioned in the center of the monitor; two peripheral boxes subtending $0.5^{\circ}$ and centered $6.75^{\circ}$ to the left and right of the fixation dot; a large solid dot subtending $0.5^{\circ}$ that served as the attentional cue; the targets $\mathrm{X}$ and + , each subtending $0.4^{\circ}$; and a white square distractor subtending $0.4^{\circ}$. It is important to note that the targets were identical in all respects, except for their rotation of $45^{\circ}$.

Figure 1 presents the sequence of events that made up a trial. At the start of each trial, the fixation dot and two peripheral boxes were presented for $800 \mathrm{msec}$. The attentional cue then appeared in one of the two peripheral boxes for $300 \mathrm{msec}$ and then was removed. After a delay of $200 \mathrm{msec}$, the cue was centered on the fixation dot for $300 \mathrm{msec}$ and then removed. Following a delay of $160 \mathrm{msec}$, a target and a distractor or a target alone was centered in a peripheral box. 


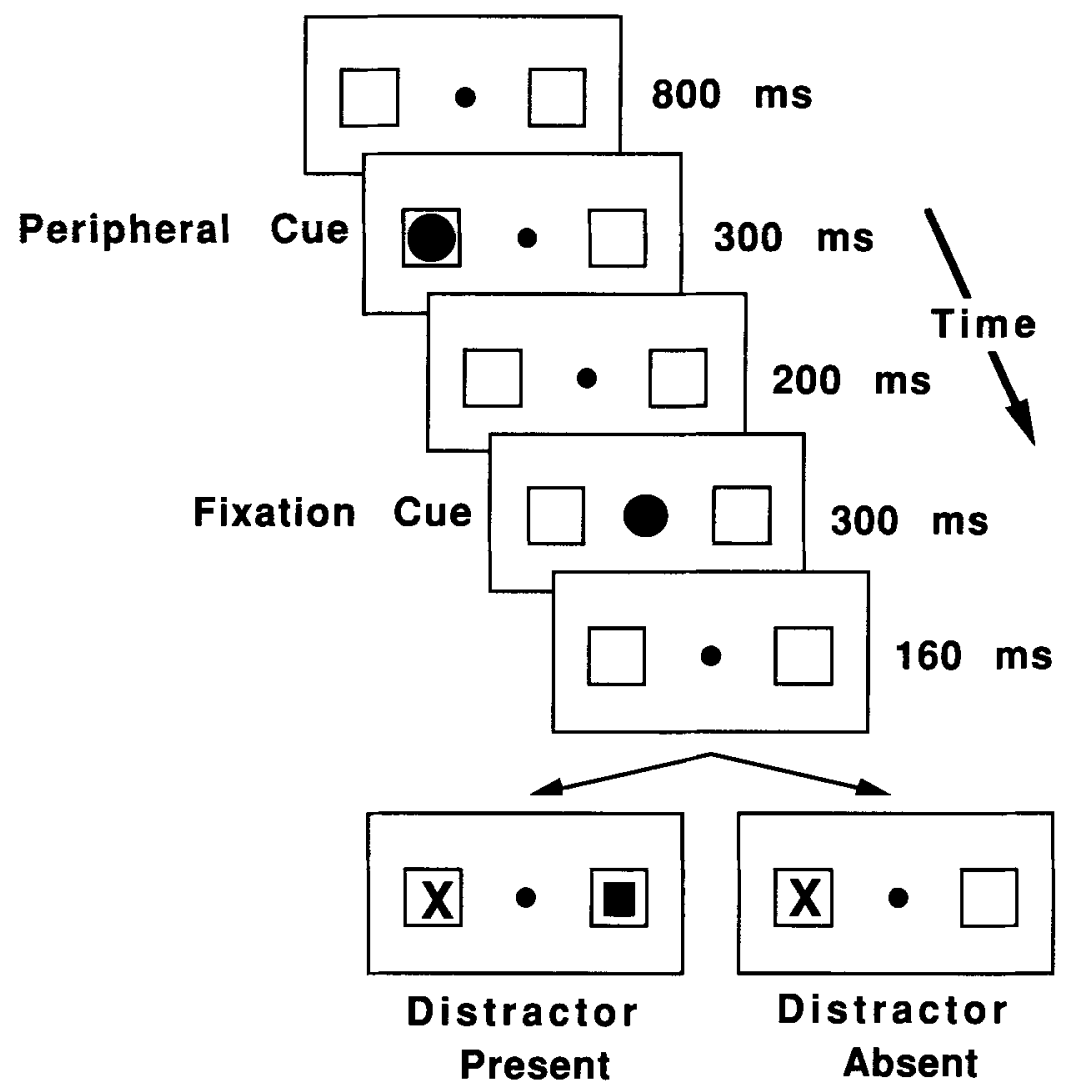

Figure 1. Illustration of a trial sequence. In the target localization task, subjects indicate with a keypress whether a target $X$ is to the left or the right of a central fixation point. In the target identification task, subjects indicate with a keypress whether the target is an $X$ or $a+$. In both tasks, target onset can co-occur with a nontarget stimulus square (distractor present) or in isolation (distractor absent).

The subjects were instructed to fixate the center dot at the start of each trial and to respond to a target stimulus by pressing one of two response keys as quickly and as accurately as possible. In the location condition, the subjects were to press the $Z$ key if the target $X$ was in the box to the left of the fixation point and the / key if the target was in the box to the right of the fixation point. In the identity condition, the subjects were to press the $Z$ key if the $X$ was presented and the / key if the + was presented. Response stimuli remained on the screen until the subject responded or $1,000 \mathrm{msec}$ had elapsed, whichever came first. If a subject pressed the wrong key or the response latency was less than $100 \mathrm{msec}$ or greater than $1,000 \mathrm{msec}$, a brief tone was sounded. The intertrial interval was $1,500 \mathrm{msec}$

Design. There were four possible test conditions: target localization without a distractor, localization with a distractor, target identification without a distractor, and identification with a distractor. Each of these test conditions was composed of 80 trials. Each of the 24 subjects received a unique order of the test conditions.

\section{Results}

The mean correct RTs are presented in Figure 2. A within-subjects analysis of variance (ANOVA) was conducted, with task (location or identity), distractor (present or absent), and cue condition (cued or uncued) as factors. There was a reliable main effect of task $[F(1,23)=$ $\left.353.7, M S_{\mathrm{e}}=2,732, p<.0001\right]$, with RTs in the identity task (489 $\mathrm{msec})$ being slower than those in the location task (347 msec), indicating that target identification required finer visual discrimination than did target localization. There was also a main effect of distractor $\left[F(1,23)=23.91, M S_{\mathrm{e}}=1,096, p<.0001\right]$, there being longer RTs when the distractor was present $(430 \mathrm{msec})$ than when it was absent $(407 \mathrm{msec})$, consistent with the view that attentional orienting is more under endogenous than under exogenous control when a distractor is present (see Pratt et al., 1997, and the General Discussion section of the present paper for detailed considerations of this issue). Finally, there was a main effect of cue condition $\left[F(1,23)=31.13, M S_{\mathrm{e}}=999, p<.0001\right]$, with cued locations having longer RTs $(431 \mathrm{msec})$ than did uncued locations ( $406 \mathrm{msec}$ ), indicating the presence of the IOR effect.

The only significant interaction was that between task and cue condition $\left[F(1,23)=10.49, M S_{\mathrm{e}}=366, p<.005\right]$, with the magnitude of the IOR effect being twice as large for the identity task ( $34 \mathrm{msec}$ ) as for the location task $(17 \mathrm{msec})$. The lack of a three-way interaction $[F(1,23)=$ $\left.1.67, M S_{\mathrm{e}}=549, p>.20\right]$ suggests that the IOR effect 


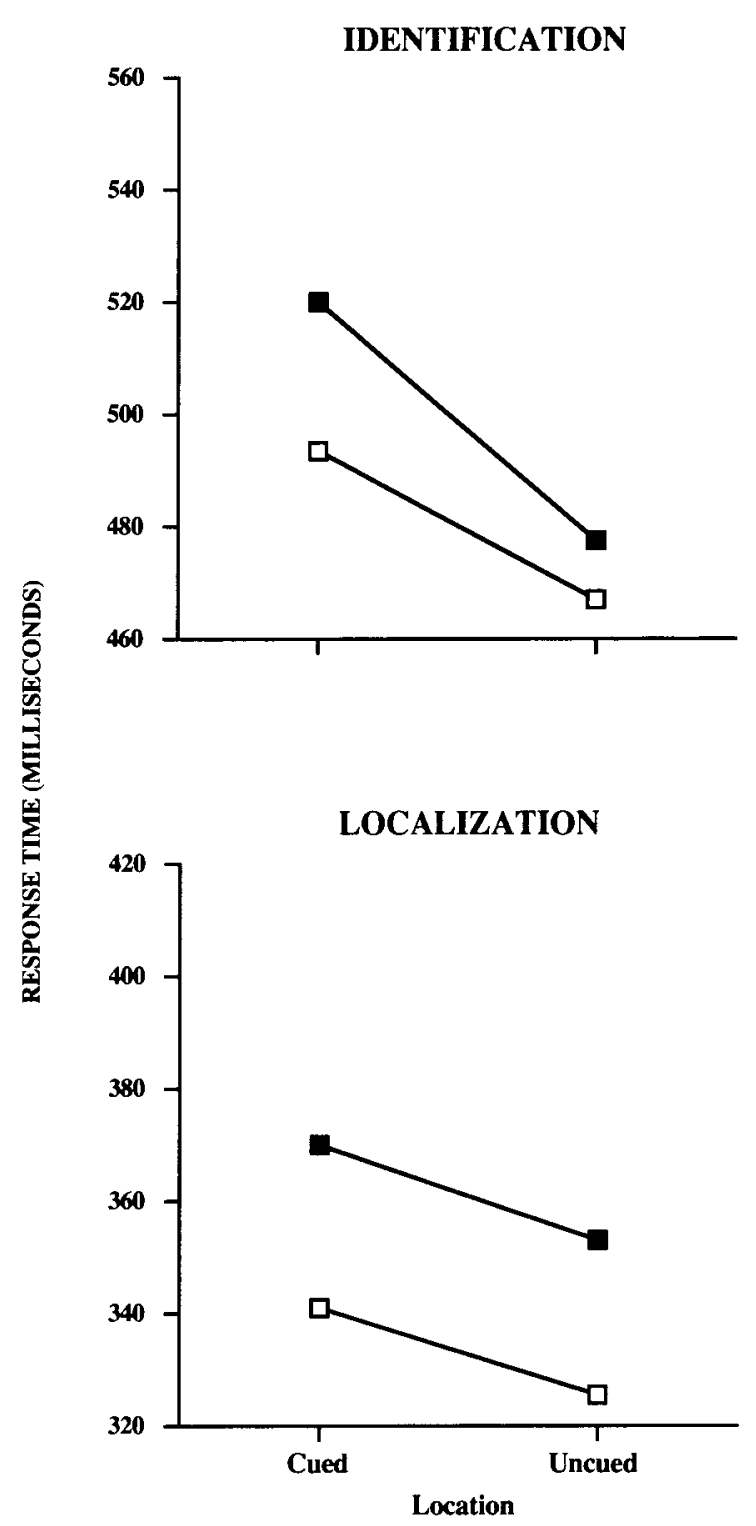

Figure 2. Response times when the task was to identify or to localize the target stimulus that appeared at a cued or an uncued location. Open squares represent trials in which the target was presented alone (distractor absent). Filled squares depict trials in which the target was presented with a distractor stimulus (distractor present).

was the same whether or not a distractor was present. This was confirmed by planned comparisons that showed that the IOR effect with and without a distractor did not differ for identity $\left[F(1,23)=2.7, M S_{\mathrm{e}}=374, p>.1\right]$ or location $(F<1)$ responses.

The percent error rates are shown in Table 1. These data were analyzed with the same ANOVA factors as those used for the RT data. None of the accuracy data contradict the RT data. There was a reliable main effect of task $\left[F(1,23)=47.92, M S_{\mathrm{e}}=6.85, p<.0001\right]$, there being a higher error rate for target identification $(8.49 \%)$ than for target localization $(1.95 \%)$. There was also a main ef- fect of distractor condition $\left[F(1,23)=7.61, M S_{\mathrm{e}}=2.72\right.$, $p<.02]$, there being a higher error rate when the distractor was present $(6.03 \%)$ than when it was absent (4.4\%). And the main effect of cue condition brushed significance $\left[F(1,23)=3.79, M S_{\mathrm{e}}=2.00, p<.07\right]$, there being a higher error rate at the cued location $(6.03 \%)$ than at the uncued location (4.4\%). This tendency for the error rate to be higher at the cued location was apparent in the identification task, resulting in a significant interaction between cue condition and target task $[F(1,23)=3.07$, $\left.M S_{\mathrm{e}}=1.06, p<.05\right]$. No other accuracy effect was significant.

\section{Discussion}

If IOR is an attentional phenomenon, it should occur for both target localization and target identification responses. On the other hand, if IOR is a motor phenomenon that is specific to target localization responses, IOR should occur only for target localization responses. The results of the present study indicate that IOR was observed for target localization and identification responses, supporting an attentional explanation of IOR and replicating Pratt et al. (1997).

Also in agreement with Pratt et al. (1997, Experiments 1 and 2), we found that the IOR effect was larger for target identification than for target localization responses. However, unlike Pratt et al. (Experiment 3), we found that adding a distractor stimulus to the target identification task did not reduce the magnitude of the IOR effect. Indeed, if anything, it increased it.

Overall, we found that adding a distractor stimulus slowed RT performance for target identification and localization responses, but it did not modulate the IOR effect for either response task. This finding conflicts directly with Pratt et al.'s (1997) hypothesis that a distractor stimulus reduces the IOR effect because orienting to a target stimulus is primarily under endogenous rather than exogenous control.

\section{EXPERIMENT 2}

In Experiment 1, we found that, if the subjects' eyes were not monitored, the IOR effect was significantly larger in the identity task than in the localization task. This finding replicates Pratt et al. (1997, Experiments 1 and 2). In Experiment 1, we also found that the presence or absence of a distractor stimulus did not affect the magnitude of the IOR effect in either response task. This conflicts with Pratt et al. (Experiment 3), who found that

Table 1

Error Rate (\%) in Experiment 1 as a Function of Task (Localization, Identification), Cue Condition (Cued, Uncued), and Distractor (Present, Absent)

\begin{tabular}{cccccc}
\hline & \multicolumn{2}{c}{ Localization } & & \multicolumn{2}{c}{ Identification } \\
\cline { 2 - 3 } \cline { 6 - 6 } Distractor & Cued & Uncued & & Cued & Uncued \\
\hline Present & 2.12 & 2.40 & & 12.20 & 7.40 \\
Absent & 1.46 & 1.77 & & 8.33 & 6.04 \\
\hline
\end{tabular}


a distractor stimulus reduces the IOR effect in the identity task. However, as was noted in the introduction, Pratt et al. confounded the presentation of a distractor stimulus with the introduction of eye monitoring. Thus, it is possible that the IOR effect was reduced in the identity condition, not because of the presentation of a distractor stimulus, but because any contribution of eye movements to the IOR effect was eliminated when eye monitoring was introduced.

The implication is that the presence or absence of eye movements can mediate an attentional IOR effect. If this is the case, it would suggest that the IOR effect may be composed of two separate components, an attentional component and a motor component. The goal of Experiment 2 was to test this hypothesis. We repeated Experiment 1 , but on this occasion, subjects' eyes were monitored, and they were instructed to make or withhold eye movement responses. In this way, we were able to test whether eye movements affect the magnitude of the IOR effect.

\section{Method}

Subjects. Sixteen undergraduate observers from the University of Toronto participated in two 1-h sessions. All the subjects had normal or corrected-to-normal vision and received course credit for their participation.

Apparatus and Procedure. The apparatus and procedure were exactly the same as those in Experiment 1 , with three notable exceptions. First, eye position was monitored throughout the experiment with a sclera-reflectance eye movement monitor (ASL model 210). Second, in one session, the subjects were instructed to make a saccadic eye movement to the target (move condition), and in the other, they were instructed to maintain central fixation (fixate condition). In both response conditions, the dependent measure was manual keypress response latency. Third, an error tone was sounded as before, with the addition that response errors now included the failure to make an eye movement to the target before a manual response was executed in the move condition and the initiation of an eye movement of $1^{\circ}$ within $1,000 \mathrm{msec}$ of target onset in the fixate condition.

Design. The design was the same as before, except that there were two test sessions, one for the move condition and one for the fixate condition. The order of conditions was counterbalanced across subjects via a Latin square design.

\section{Results}

The mean correct RTs are presented in Figure 3. A within-subject ANOVA was conducted, with task (location or identity), distractor (present or absent), cue condition (cued or uncued), and eye movement condition (move or fixate) as factors. As is suggested by Figure 3, the eye movement condition had a significant effect on RT performance $\left[F(1,15)=16.42, M S_{\mathrm{e}}=9,008, p<.002\right]$, with RT being slower in the move condition $(513 \mathrm{msec})$ than in the fixate condition $(465 \mathrm{msec})$. All the other main effects were significant, as they were in Experiment 1. There was a reliable main effect of task $[F(1,15)=176.51$, $\left.M S_{\mathrm{e}}=7,314, p<.0001\right]$, with RTs in the identity task $(560 \mathrm{msec})$ being slower than those in the location task $(418 \mathrm{msec})$. There was also a main effect of distractor $\left[F(1,15)=51, M S_{\mathrm{e}}=1,101, p<.0001\right]$, there being

\section{IDENTIFICATION}

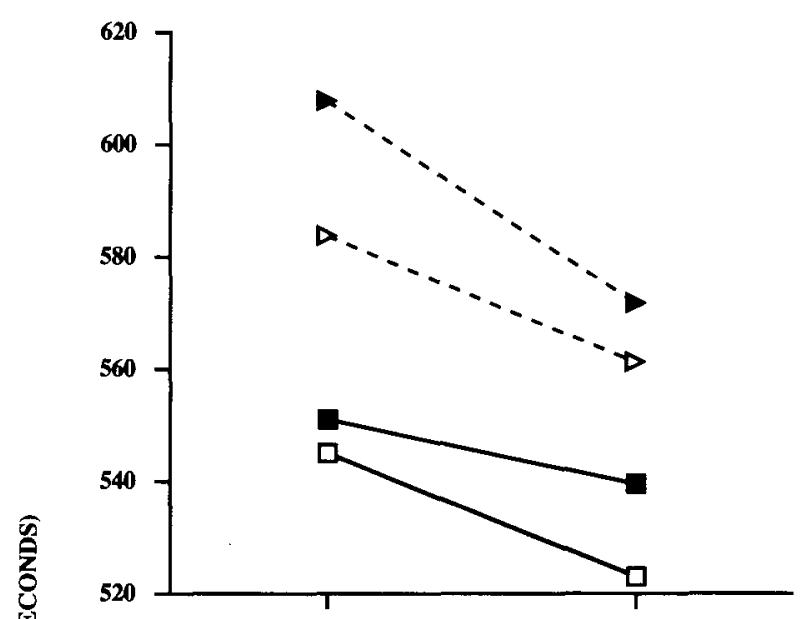

\section{LOCALIZATION}

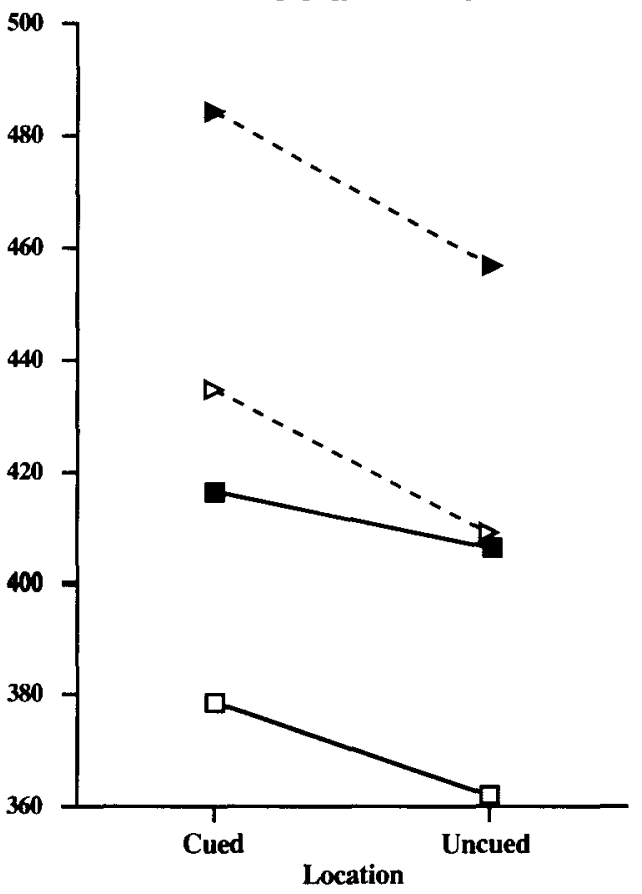

Figure 3. Response times when the task was to identify or to localize the target stimulus that appeared at a cued or an uncued location. Open squares represent trials in which the target was presented alone (distractor absent). Filled squares depict trials in which the target was presented with a distractor stimulus (distractor present). Dashed lines represent the eye movement condition, and solid lines the fixate condition.

longer RTs when the distractor was present (504 msec) than when it was absent $(475 \mathrm{msec})$. And finally, the IOR effect was observed $\left[F(1,15)=85.08, M S_{\mathrm{e}}=341, p<\right.$ $.0001]$, with cued locations having longer RTs $(500 \mathrm{msec})$ than uncued locations $(479 \mathrm{msec})$.

There was a significant interaction between target task and distractor condition $\left[F(1,15)=13.68, M S_{\mathrm{e}}=1,105\right.$, $p<.005]$, with the appearance of a distractor stimulus 
slowing RT far more in the localization task $(46 \mathrm{msec})$ than in the identification task $(15 \mathrm{msec})$. There was also an interaction between eye movement and cue conditions $\left[F(1,15)=5.27, M S_{\mathrm{e}}=495, p<.05\right]$, with the IOR effect being almost twice as large in the move condition $(27 \mathrm{msec})$ as in the fixate condition $(15 \mathrm{msec})$. Finally, there was a three-way interaction between eye movement, cue, and distractor conditions $\left[F(1,15)=4.49, M S_{\mathrm{e}}=\right.$ $244, p<.05]$. Looking at Figure 4 , one can see that when the subjects maintained central fixation, the presence of a distractor stimulus reduced the IOR effect significantly $[F(1,15)=6, p<.05]$. However, when the subjects made eye movements, the presence of a distractor stimulus did not affect the IOR effect $[F(1,15)=1.6, p>.20]$.

The percent error rates are shown in Table 2. Eye movements and keypress errors were analyzed with the same ANOVA factors as those used for the RT data. None of the accuracy data contradict the RT data. For eye movement errors, there were no significant main effects (all $F \mathrm{~s}<3$, all $p \mathrm{~s}>.10$ ). There were significant interactions between cue and distractor conditions $[F(1,15)=$ $\left.6.14, M S_{\mathrm{e}}=16.81, p<.05\right]$, and between cue and distractor conditions and target task $\left[F(1,15)=6, M S_{\mathrm{e}}=\right.$ $10.17, p<.05]$, reflecting the fact that there was a significant difference between the error rates at cued $(4.7 \%)$ and uncued $(7.6 \%)$ locations when a distractor was absent in the target identification task. For keypress errors, the eye movement condition had a significant effect on performance $\left[F(1,15)=5.48, M S_{\mathrm{e}}=60.24, p<.05\right]$, there being more errors in the move condition $(6.62 \%)$ than in the fixate condition ( $4.35 \%)$. This was due to the much larger number of anticipatory or wrong-direction eye movements that were made in the move condition (there were virtually no eye movement errors in the fixate condition). There was also a significant main effect of task $\left[F(1,15)=35.45, M S_{\mathrm{e}}=117.9, p<.0001\right]$, there being a higher error rate for target identification (9.52\%) than for target localization (1.44\%). And finally, there was a main effect of distractor condition $[F(1,15)=6.53$, $\left.M S_{\mathrm{e}}=77.25, p<.05\right]$, with a higher error rate when the distractor was present $(6.89 \%)$ than when it was absent $(4.08 \%)$. No other main effect or interactions were significant, although, as in Experiment 1, there was a tendency for the error rate to be higher at the cued location than at the uncued location in the identification task, resulting in a marginal interaction between cue condition and target task $\left[F(1,15)=4.02, M S_{\mathrm{e}}=5.94, p<.07\right]$.

\section{Discussion}

One of the primary goals of Experiment 2 was to determine whether the attentional IOR effect was greater when eye movements were executed to a target stimulus. The data on this issue were clear-cut. The magnitude of the IOR effect was nearly doubled when the subjects made eye movements to the target stimulus.

We also discovered that when the contribution of eye movements was accounted for, the magnitude of the IOR effect was equivalent for identity and localization responses. This supports our hypothesis that, when the IOR effect was larger for identification responses (Pratt et al., 1997, Experiments 1 and 2; Experiment 1 of the present study), it was because the subjects were executing eye movements in the target identification task, but not in the target localization task.

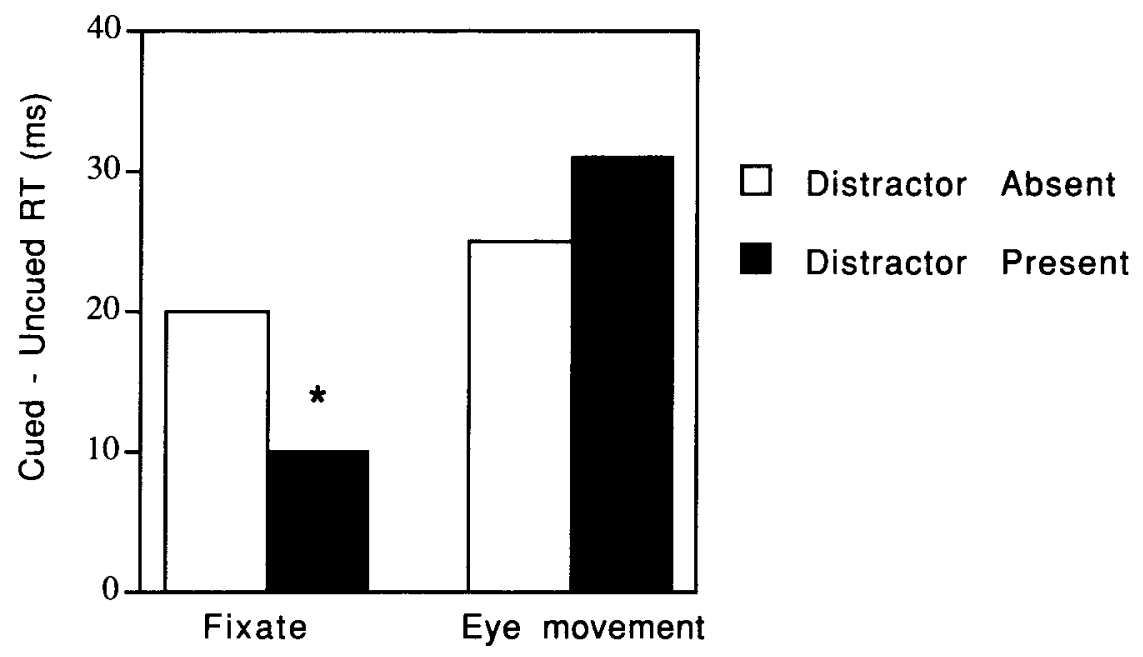

Figure 4. Magnitude of inhibition of return (cued - uncued response time [RT]) collapsed across response task. The asterisk indicates that, in the fixate condition, there was a significant difference in the IOR effect between distactor absent and distractor present. In the eye movement condition, there was no significant difference between distactor absent and distractor present. 
Table 2

Eye Movement and Keypress Error Rates (\%) in Experiment 2 as a Function of Eye Movement Condition (Fixate, Move), Task (Localization, Identification), Cue Condition (Cued, Uncued), and Distractor (Present, Absent)

\begin{tabular}{|c|c|c|c|c|c|c|c|c|}
\hline \multirow[b]{3}{*}{ Distractor } & \multicolumn{4}{|c|}{ Fixate } & \multicolumn{4}{|c|}{ Move } \\
\hline & \multicolumn{2}{|c|}{ Localization } & \multicolumn{2}{|c|}{ Identification } & \multicolumn{2}{|c|}{ Localization } & \multicolumn{2}{|c|}{ Identification } \\
\hline & Cued & Uncued & Cued & Uncued & Cued & Uncued & Cued & Uncued \\
\hline \multicolumn{9}{|c|}{ Eye Movement Errors (\%) } \\
\hline Present & 6.45 & 6.06 & 8.00 & 5.86 & 2.93 & 5.64 & 2.54 & 4.88 \\
\hline Absent & 5.86 & 8.40 & 5.47 & 7.23 & 8.00 & 5.64 & 3.91 & 8.00 \\
\hline \multicolumn{9}{|c|}{ Keypress Errors (\%) } \\
\hline Present & 0.98 & 1.17 & 9.18 & 8.98 & 2.93 & 2.54 & 15.23 & 14.06 \\
\hline Absent & 0.59 & 0.98 & 6.64 & 6.25 & 1.37 & 0.98 & 9.57 & 6.25 \\
\hline
\end{tabular}

Finally, it should be noted that when the subjects maintained fixation, a distractor stimulus reduced the IOR effect in both the target identification and the localization tasks. This is consistent with the original prediction of Pratt et al. (1997), that the IOR effect is reduced when a distractor stimulus is presented, because covert attention to a target stimulus is primarily under endogenous control, rather than exogenous control.

\section{GENERAL DISCUSSION}

In two experiments, we examined the IOR effect when the task was either target localization or target identification. In each experiment, a robust IOR effect was observed for both response tasks. This finding replicates the results of Pratt et al. (1997) and demonstrates again that the IOR effect is an attentional phenomenon. As was noted in the introduction, if IOR were specific to motor responses that localize the target stimulus, as was hypothesized by Klein and Taylor (1994), IOR should only have been observed in the target localization task.

However, we did discover, in Experiment 2, that the IOR effect is increased when subjects are required to localize a target stimulus with an eye movement. This suggests that an oculomotor process can contribute to the IOR effect. It is important to note that one might argue that the increase we observed in the IOR effect when oculomotor and manual responses were made to the target simply reflects the sum of two attentionally inhibited responses-that is, an oculomotor response and a manual response. However, this position is not supported by the data. Recall that, in Experiment 2, we found that IOR increased when an eye movement was made to the target stimulus, and we also found that the attentional effect of adding a distractor stimulus was abolished. The fact that the attention-based distractor effect was eliminated when the subjects made eye movements to the target stimulus demonstrates that the greater IOR effect found in the eye movement condition does not simply reflect the sum of two attentionally inhibited responses (oculomotor and manual). If the effects were additive, the attention-based distractor effect should be preserved and magnified when subjects made eye movements to the target. Instead, the distractor effect was eliminated.

This finding, of course, raises the question as to why an oculomotor response would negate the attentional distractor effect. One possibility is that there is no attentional IOR effect when an eye movement is made to the target stimulus. An alternative possibility is that the oculomotor IOR effect may be masking the attentional effect. With regard to the latter, it should be noted that if delays owing to attentional IOR and oculomotor IOR occur in parallel, the total RT should be delayed only by the longer delay, presumably the oculomotor effect. This interpretation makes a somewhat surprising prediction: If subjects were instructed to only move their eyes (no keypress), IOR should be the same as when subjects make both keypresses and eye movements. ${ }^{1}$ Teasing this issue apart will be an important goal for our future investigations. At present, however, the key point to note is that our investigation reveals that an IOR effect can be composed of two distinct processes: a motor component that is specific to oculomotor target localization responses and an attentional component that generalizes across different response tasks.

The notion that there may be inhibition specific to the oculomotor system is consistent with the findings of Abrams and Dobkin (1994) and Pratt and Abrams (1997). In both of these studies, the subjects made eye movement responses to a centrally presented endogenous target (an arrow indicating the box to which they should move their eyes). IOR was found in these studies, despite the fact that no peripheral target was presented. These studies concluded that there is inhibition within the motor system (i.e., the oculomotor system) and that this inhibition is functionally different from attentional inhibition (i.e., motor inhibition is specific to spatial locations and is encoded in retinal coordinates). Taken together, the findings of the present experiments and those of Abrams and Dobkin and of Pratt and Abrams provide strong support for separate attentional and motor components to the IOR effect.

In addition, it is important to note that the present study indicates that oculomotor IOR occurs both when an eye 
movement response is driven by an endogenous signal (e.g., distractor present in the target identification task) and when the oculomotor response is driven by an exogenous signal (e.g., distractor absent in the target localization task). This finding is consistent with the seminal work of Rafal, Calabresi, Brennan, and Sciotto (1989, Experiment 4), who found that IOR would result from oculomotor activation, regardless of whether it was produced by endogenous signals or exogenously. Similarly, our proposal that motor-based IOR is specific to activation of the oculomotor system is convergent with Rafal et al.'s (Experiment 5) finding that specific activation of the manual response system does not produce IOR.

Finally, we found that when eye movements are not executed, the IOR effect is larger when a target is presented in isolation than when a target is presented with a nontarget. This suggests that the IOR effect may be larger for reflexive shifts of attention to abrupt stimulus onsets. Presumably, the presentation of a peripheral cue triggers exogenous (reflexive) orienting to that location. Attention is then subsequently inhibited from returning to that location. When a target appears in isolation, it will also trigger reflexive orienting. On the other hand, when a target appears with a distractor stimulus, orienting to the target may now be more volitional than reflexive. ${ }^{2}$ Thus, it seems possible that our finding that the IOR effect is larger when a target is presented in isolation than when it is presented with a distractor stimulus may be due to the fact that the IOR effect is larger for reflexive orienting than for volitional orienting.

One interesting implication of the above conclusion is that it may help to explain why evidence of IOR has been difficult to find in perceptual tasks, such as the judgment of temporal order (TOJ; see Gibson \& Egeth, 1994; Klein, Schmidt, \& Müller, 1998; Maylor, 1985) or illusory line motion (ILM; see Schmidt, 1996). The idea here is that, if attention is inhibited from operating on certain channels of information, there should be perceptual consequences of this inhibition (e.g., information may arrive more slowly in the affected channels). Unfortunately, perceptual tasks, such as TOJ and ILM tasks, have failed to produce any strong evidence that IOR is attention based. However, it is possible that these tasks do not elicit exogenous attention. For instance, in the TOJ task, two stimuli are presented close together in time, a situation that is very similar to the distractor-present condition in the present study. Interestingly, Gibson and Egeth report that IOR can be observed in the TOJ task, but only when the two stimuli are separated by at least $100 \mathrm{msec}$ (see Klein et al., 1998, for a detailed discussion of Gibson \& Egeth, 1994).

In conclusion, a motor-based explanation cannot account for our finding that IOR occurs in target localization and identification tasks when eye movements are controlled. As was noted by Pratt et al. (1997), such a finding strongly supports an attentional account of IOR.
Nevertheless, our discovery that eye movements to a target stimulus increase the magnitude of IOR suggests that IOR can be composed of two, separable processes: a motor component that is specific to oculomotor target localization responses and an attentional component that generalizes across different response tasks. Finally, our data suggest that the IOR effect varies for different forms of covert orienting, with IOR being larger for exogenous orienting than for endogenous orienting.

\section{REFERENCES}

Abrams, R. A., \& Dobkin, R. S. (1994). Inhibition of return: Effects of attentional cueing on eye movement latencies. Journal of Experimental Psychology: Human Perception \& Performance, 20, 467-477.

Briand, K. A., \& KLein, R. M. (1987). Is Posner's "beam" the same as Treisman's "glue"? On the relation between visual orienting and feature integration theory. Journal of Experimental Psychology: Human Perception \& Performance, 13, 228-241.

Cheal, M. L., \& Lyon, D. R. (1991). Central and peripheral cuing of forced-choice discrimination. Quarterly Journal of Experimental Psychology, 43A, 859-880.

Corbetta, M., Miezin, F., Shulman, G. L., \& Petersen, S. E. (1993). A PET study of visuospatial attention. Journal of Neuroscience, 13 , 1202-1226.

Gibson, B. S., \& EGETH, H. (1994). Inhibition and disinhibition of return: Evidence from temporal order judgments. Perception \& Psychophysics, 56, 669-680.

JoNIDES, J. (1981). Voluntary versus automatic control over the mind's eye's movement. In J. [B.] Long \& A. [D.] Baddeley (Eds.), Attention and performance $I X$ (pp. 187-203). Hillsdale, NJ: Erlbaum.

Kingstone, A., Grabowecky, M., Mangun, G. R., Valsangkar, M., \& Gazzaniga, M. S. (1997). Paying attention to the brain: The study of selective visual attention in cognitive neuroscience. In J. Burak \& J. Enns (Eds.), Attention, development, and psychopathology (pp. 263287). New York: Guilford.

Kiein, R. M., Kingstone, A., \& Pontefract, A. (1993). Orienting of visual attention. In $\mathrm{K}$. Rayner (Ed.), Eye movements and visual cognition: Scene perception and reading (pp. 46-65). New York: SpringerVerlag.

Klein, R. M., Schmidt, W. C., \& Müller, H. J. (1998). Disinhibition of return: Unnecessary and unlikely. Perception \& Psychophysics, 60, 862-872.

KIEIN, R. M., \& TAYLOR, T. L. (1994). Categories of cognitive inhibition with reference to attention. In D. Dagenbach \& T. H. Carr (Eds.), Inhibitory processes in attention, memory, and language (pp. 113150). New York: Academic Press.

MAYLOR, E. A. (1985). Facilitatory and inhibitory components of orienting in visual space. In M. I. Posner \& O. S. M. Marin (Eds.), Attention and performance XI (pp. 189-204). Hillsdale, NJ: Erlbaum.

Müller, H. J., \& Findlay, J. M. (1988). The effect of visual attention on peripheral discrimination thresholds in single and multiple element displays. Acta Psychologica, 69, 129-155.

Müller, H. J., \& RabbitT, P. M. A. (1989). Reflexive and voluntary orienting of attention: Time course of activation and resistance to interruption. Journal of Experimental Psychology: Human Perception \& Performance, 15, 315-330.

Posner, M. I., \& Cohen, Y. P. C. (1984). Components of visual orienting. In H. Bouma \& D. G. Bouwhuis (Eds.), Attention and performance X: Control of language processes (pp. 531-556). Hillsdale, NJ: Erlbaum.

PosNer, M. I., \& PeTERSON, S. (1990). The attention system of the human brain. Annual Reviews of Neuroscience, 13, 25-42.

Pratt, J., \& Abrams, R. A. (1997, November). Retinal coding of inhibited eye movements to previously attended location. Poster presented at the 36 th Annual Meeting of the Psychonomic Society, Philadelphia. Pratt, J., Kingstone, A., \& Khoe, W. (1997). Inhibition of return in 
location- and identity-based choice decision tasks. Perception \& Psychophysics, 59, 964-971.

Rafal, R. D., Calabresi, P. A., Brennan, C. W., \& Sciolto, T. K. (1989). Saccade preparation inhibits reorienting to recently attended locations. Journal of Experimental Psychology: Human Perception \& Performance, 15, 673-685.

RAFAL, R. [D.], \& HeNIK, A. (1994). The neurology of inhibition: Integrating controlled and automatic processes. In D. Dagenbach \& T. H. Carr (Eds.), Inhibitory processes in attention, memory and language (pp. 1-51). New York: Academic Press.

ScHMidT, W. C. (1996). Inhibition of return is not detected using illusory line motion. Perception \& Psychophysics, 58, 883-898.

Tsal, Y. (1989). Further comments on feature integration: A reply to Briand and Klein. Journal of Experimental Psychology: Human Perception \& Performance, 15, 407-410.

YanTIS, S. (1996). Attentional capture in vision. In A. F. Kramer, M. G. H. Coles, \& G. D. Logan (Eds.), Converging operations in the study of visual selective attention (pp. 45-76). Washington, DC: American Psychological Association.

YANTIS, S., \& Jonides, J. (1990). Abrupt visual onsets and selective at- tention: Voluntary versus automatic allocation. Journal of Experimental Psychology: Human Perception \& Performance, 16, 121-134.

\section{NOTES}

1. We are grateful to Tram Neill for this point.

2. Recall that because the target was harder to discriminate in the identification task than in the localization task, the attentional demand (and the desire to execute an eye movement to the target) was higher in the identification task than in the localization task. It follows that the attentional effect of a distractor will be higher in the identification task than in the localization task. Consistent with this prediction, a post hoc analysis of the data in Experiment 2 revealed that the attentional effect of a distractor was significant for target identification $(p<.03)$, but only marginally significant for target localization $(.10>p>.05)$. This marginal effect of a distractor dovetails with the nonsignificant effect of a distractor observed in Experiment 1 for target localization.

(Manuscript received January 8, 1998; revision accepted for publication August 24, 1998.) 